\title{
Diskectomy during Pregnancy: Case Report and Review of the Literature
}

\author{
Michel Kanas ${ }^{1}$ Hugo Kunzle ${ }^{1}$ Delio E. Martins ${ }^{1}$ Luiz A. Kirsch ${ }^{2}$ Eduardo B. Puertas ${ }^{1}$ \\ Marcelo Wajchenberg ${ }^{1}$ \\ ${ }^{1}$ Spine Group from Department of Orthopedics and Traumatology, \\ Universidade Federal de Sao Paulo (Unifesp), Sao Paulo, Brazil \\ 2 Department of Anesthesia, Hospital Israelita Albert Einstein, Sao \\ Paulo, Brazil \\ Address for correspondence Michel Kanas, MD, Al. Joaquim Eugênio \\ de Lima, 1656, ap. 141, Jardim Paulista, São Paulo-SP, Brazil, CEP \\ 01403-002 (e-mail: michelkanas@hotmail.com).
}

Global Spine J 2015;5:130-134.

\section{Abstract \\ Keywords \\ - pregnancy complications \\ - intervertebral disk displacement \\ - anesthesia}

Study Design Case report.

Objective The purpose of this report is to discuss the management of a disk herniation during pregnancy and the indication and particularities of surgery in this situation. Methods We describe a case of diskectomy performed in a 35-year-old woman at 18 weeks of gestation. After 4 weeks of trying to manage the disk herniation with rest and medications without success, the muscle strength of the L5 right root decreased to grade 4, and the patient was not responding to intravenous analgesia. After discussion with the patient and family, a decision was made to perform the diskectomy.

Results After surgery, the patient's pain lessened, and the Lasegue test became negative. Two weeks after the procedure, the patient's muscle strength was normal. In the 40th week of pregnancy, the patient gave birth without any complications.

Conclusion When necessary, diskectomy can be indicated and performed during pregnancy. However, appropriate precautions must be taken. Awareness of these precautions is important for the success of the procedure and for the well-being of the mother and the newborn.

\section{Introduction}

Low back pain is a common symptom in pregnancy and may be present in up to $56 \%$ of pregnant women. ${ }^{1,2}$ Previous studies correlated low back pain and pelvic pain with increased levels of relaxin, a hormone produced mainly by the corpus luteum during pregnancy. However, biomechanical changes, weight gain, and sagittal imbalance are also possible etiologies. ${ }^{3}$

Radiculopathy caused by disk herniation during pregnancy is rare, affecting 1 in 10,000 pregnant women. ${ }^{4}$ There are some important peculiarities to be considered in the management of this condition during pregnancy, especially when a surgical approach is necessary. The main issues to consider are which drugs and diagnostic tests are safe during gestation, surgical indications, the best time and technique for the

procedure, the appropriate anesthesia, and following the pregnancy after surgery.

There are few reports in the literature about this subject, and at this time, no protocol has been established for this situation. ${ }^{1,5}$

\section{Case Report}

A 35-year-old female presented with intense episodes of low back pain with sciatica of the right leg since the 12th week of gestation; she was treated with drugs and home rest. In the 14th week of pregnancy, the pain intensified and did not respond to oral medication. The patient visited the emergency room several times to receive intravenous analgesia without remission of symptoms. Two weeks later, she presented

(c) 2015 Georg Thieme Verlag KG Stuttgart · New York
DOI http://dx.doi.org/ 10.1055/s-0034-1387178. ISSN 2192-5682. 


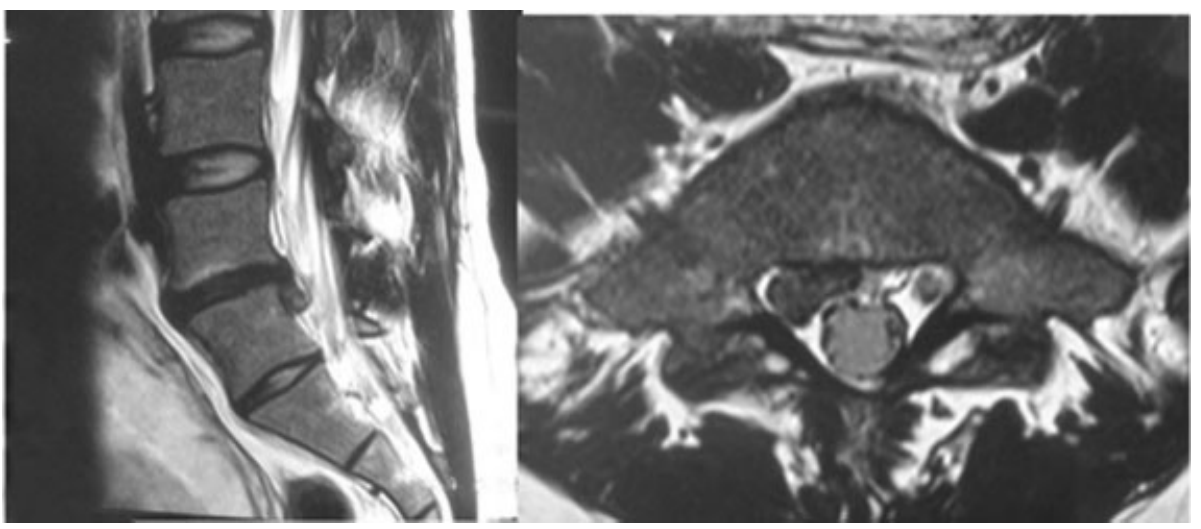

Fig. 1 Magnetic resonance image: sagittal view on the left and axial view on the right, demonstrating the L4-L5 disk extrusion with caudal migration compressing the $L 5$ right nerve.

with a positive Lasegue maneuver and neurologic deficit with decreased muscle strength (grade 4) of the right L5 root. Magnetic resonance imaging (MRI) was performed, highlighting an extruded herniation L4-L5 in the lateral recess with caudal migration (-Fig. 1).

After discussion with the patient and her family, a diskectomy was performed in the 18 th week of gestation. The patient was placed under general anesthesia in the prone position with cushions to avoid abdominal compression (-Fig. 2). Using anatomical references (iliac crest), the L4L5 level was found without using fluoroscopy to avoid radiation exposure to the fetus. The fetal heartbeat (FHB) was not monitored during the procedure, which lasted 1 hour and 30 minutes. Only the herniated fragment was removed.

After the surgery, both FHB monitoring and ultrasound were normal. The patient's pain lessened, and the Lasegue test became negative. Two weeks after the procedure, the patient's muscle strength was normal.

In the 40th week of pregnancy, the patient had a cesarean delivery due to functional dystocia and gave birth to a baby weighing $3.6 \mathrm{~kg}$. Apgar scores were 10/10 at 1 and 5 minutes, respectively, and no complications were noted.

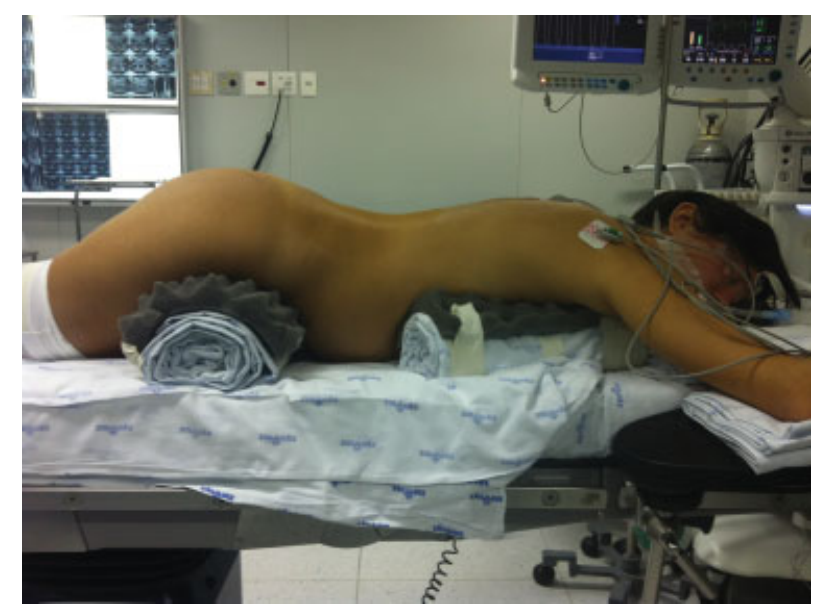

Fig. 2 Intraoperative photo demonstrating the patient positioned over cushions to prevent abdominal compression.

\section{Discussion}

Guidelines for the treatment of lumbar disk herniation are well defined and established. However, this case raised several unique considerations.

When a patient presents with signs of radicular compression, imaging must be performed to confirm disk herniation. MRI is considered the gold standard in this situation.

There are no studies demonstrating harmful effects of MRI during pregnancy. However, the American College of Radiology recommends to avoid this exam during the first trimester and to never make use of contrast agent (gadolinium). When MRI is necessary in the first trimester, the risks and benefits should be measured and explained to the expectant mother so that she may make an informed choice. ${ }^{6-8}$

According to the American Congress of Obstetricians and Gynecologists (ACOG) guidelines, MRI is not associated with known adverse fetal effects, and the use of paramagnetic contrast agents during MRI has not been studied in pregnant women. Animal studies have demonstrated increased rates of spontaneous abortion, skeletal abnormalities, and visceral abnormalities when given at two to seven times the recommended human dose. It is not known if these compounds are excreted in human milk. Generally, these agents should be used during pregnancy only if the potential benefit justifies the potential risk to the fetus as demonstrated in animal studies. ${ }^{9}$

The exposure to ionizing radiation from X-rays can result in the following three harmful effects: (1) cell death and teratogenic effects, (2) carcinogenesis, (3) genetic effects or mutations in germ cells. There is little to no information to estimate either the frequency or magnitude of adverse genetic effects on future generations; these effects are associated with high-dose exposure. ${ }^{9}$

The ACOG guidelines for X-ray exposure during pregnancy suggest the following:

1. Women should be counseled that X-ray exposure from a single diagnostic procedure does not result in harmful fetal effects. Specifically, exposure to less than 5 rad has not been associated with an increase in fetal anomalies or pregnancy loss. 
Table 1 Food and Drug Administration risk classification for drug use in pregnancy

\begin{tabular}{|l|l|}
\hline A & Controlled studies in women did not show fetal or maternal risk in any period. \\
\hline B & $\begin{array}{l}\text { Controlled studies in animals did not show fetal risk, and there are no controlled studies in women. No evidence of } \\
\text { risk in humans. }\end{array}$ \\
\hline C & $\begin{array}{l}\text { Controlled studies in animals did show adverse effects, but there are no controlled studies in humans. These drugs } \\
\text { should be given only if the potential benefit justifies the potential risk to the fetus, but the risk cannot be ruled out. }\end{array}$ \\
\hline D & $\begin{array}{l}\text { Positive evidence of human fetal risk exists. However, the benefits of use in pregnant women may be acceptable } \\
\text { despite the risk (e.g., if the drug is needed for a life-threatening condition or for a serious disease for which safer } \\
\text { drugs cannot be used or are ineffective). }\end{array}$ \\
\hline $\mathrm{X}$ & $\begin{array}{l}\text { Contraindicated in pregnancy. Studies in animals or humans have demonstrated fetal abnormalities, or evidence } \\
\text { of fetal risk exists based on human experience, or both, and the risk to pregnant women clearly outweighs any } \\
\text { possible benefit. These drugs are contraindicated in women who are or may become pregnant. }\end{array}$ \\
\hline
\end{tabular}

Adapted from Friedman JM. Report of the Teratology Society Public Affairs Committee symposium on FDA classification of drugs. Teratology $1993 ; 48: 5-6 .^{20}$

2. Concern about the possible effects of high-dose ionizing radiation exposure should not prevent medically indicated diagnostic X-ray procedures from being performed on a pregnant woman. During pregnancy, other imaging procedures not associated with ionizing radiation (e.g., ultrasonography, MRI) should be considered instead of X-rays when appropriate.

\section{Conservative Treatment}

The conservative treatment for disk herniation is based on physiotherapy, rest, drugs, and epidural injections. The American Food and Drug Administration classified the drugs for use in pregnancy into five categories (-Table 1). Analgesics (nonopioids and opioids), anti-inflammatories (nonsteroids and steroids), muscle relaxants, and anticonvulsants are commonly used (-Table 2). The epidural injection of steroids follows the same recommendations as the use of oral steroids and should be avoided in the first trimester.

Many physiotherapy resources have proven to be effective in low back pain treatment during pregnancy, such as hydrotherapy, stretching, acupuncture, global postural education, and core training. Low-intensity aerobic exercises can also be beneficial. The physiotherapist should avoid a large range of motion because the level of relaxin hormone is high, and articulations may be more flexible than usual. Continuous or pulsed ultrasound and electrical stimulation should not be applied to the lower back or abdomen. ${ }^{10}$

\section{Surgical Treatment}

The absolute indications of diskectomy during pregnancy are the same as for any patient. Therefore, in cases of cauda equina syndrome or progressive neurologic deficit, failure to perform the surgical procedure may result in permanent sequelae. The procedure is considered emergent in the first situation and urgent in the second.

Excision of ovarian cysts, breast biopsy, appendectomy, and surgery related to trauma are the most common surgical procedures performed during pregnancy, but when considering only the first trimester, laparoscopy for gynecologic indications has the highest incidence. The rate of nonobstetric surgery is $\sim 1$ to $2 \%$. Cholecystectomy and appendectomy are the most common acute abdominal procedures. ${ }^{11-14}$

Mazze and Källén conducted a study of 5,045 patients who underwent a nonobstetric surgical procedure during pregnancy; results showed similar rates of congenital anomalies and stillbirth to those of pregnant patients not subjected to any procedure. However, as a result of preterm delivery or intrauterine growth restriction, a higher incidence of low and very low birth weight was found in the surgical group.

Table 2 Main drugs used for disk herniation treatment

\begin{tabular}{|l|l|l|l|}
\hline Drugs & Type & Class & Observation \\
\hline Acetaminophen & Nonopioid analgesic & B & More than 4 g/d, for a long period, class D \\
\hline Codeine/tramadol & Opioid analgesics & C & $\begin{array}{l}\text { Risks of respiratory tract malformation } \\
\text { and hypospadias in the 1st trimester }\end{array}$ \\
\hline Diclofenac/ibuprofen & Nonsteroidal anti-inflammatory drug & B & $\begin{array}{l}\text { Class D in the 3rd trimester; potential for } \\
\text { causing premature closure of the ductus } \\
\text { arteriosus }\end{array}$ \\
\hline Prednisone/prednisolone & Glucocorticoids & C/D & $\begin{array}{l}\text { In the 1st trimester, can cause cleft lip and } \\
\text { palate }\end{array}$ \\
\hline Cyclobenzaprine & Muscle relaxant & B & Compatible \\
\hline Pregabalin & Anticonvulsant & C & No controlled studies in humans \\
\hline
\end{tabular}

Adapted from Kulay L Jr. Medicamentos na gravidez e lactação. 3rd ed. São Paulo, Brazil: Editora Manole; 2012. ${ }^{21}$ 
Additionally, more live-born infants died within the first 7 days of life in the surgical group. ${ }^{15}$

Elective surgery should not be performed during pregnancy. When possible, surgery should be avoided during the first trimester, especially during the period of organogenesis. The second trimester is optimal to perform surgery because the risk of preterm labor is lowest at that time. The management and timing of most acute surgical procedures should mimic that for nonpregnant patients. ${ }^{12}$

From the 34th to 36th gestational weeks, Han et al suggested performing cesarean delivery or inducing normal delivery; the procedure may be followed by diskectomy in the same surgery or soon after. ${ }^{5}$

In our case, because the patient's symptoms were not improving, her pain was so excruciating that even intravenous drugs were ineffective, and her neurologic standard was becoming worse, we chose the surgical approach after discussions with the patient and her family. We performed an open microdiskectomy, which is the gold standard and our routine procedure. Consideration may be given to an endoscopic approach, as a case report in the literature describes it as safe and effective in a pregnant patient. ${ }^{16}$

\section{Anesthesia}

The selection of the type of anesthesia to be used must be guided by maternal indications and the site and nature of the surgery. No study has found an association between improved fetal outcome and any specific anesthetic technique except for a single retrospective chart analysis in which the use of general anesthesia was associated with a significantly lower birth weight despite similar gestational age at delivery. ${ }^{12}$

Pregnant patients pose unique risks during general anesthesia, both to the mother (difficult airway aspiration) and the fetus (potential drug exposure, preterm labor). For these reasons, many anesthesiologists try to avoid general anesthesia if at all possible and instead use regional anesthetics.

However, in cases of radiculopathy by root compression (disk herniation) with neurologic commitment, neuraxial anesthesia would most likely be a poor choice because it may worsen the preexisting neurologic deficit, as described by Brown and Brookfield in a case report. ${ }^{17}$

The goals of anesthetic management in pregnant women are maternal safety and avoidance of fetal hypoxia and early labor. Of the commonly used drugs, only benzodiazepines have been correlated to fetal malformation and should be avoided. ${ }^{13}$

From 18 to 20 weeks of gestation, there are some concerns with patient positioning. When lying supine, the uterus can compress the inferior vena cava, reducing the venous return and cardiac output by 25 to $30 \%$; for this reason, it is essential to displace the uterus laterally during any operation after this period. ${ }^{12}$ In our case, the patient was lying prone, and we attempted to avoid direct compression of the abdomen by placing high cushions under the shoulders and iliac crest as shown in - Fig. 2.

In their case series, Han et al performed surgeries in ventral decubitus in the first trimester and at the beginning of the second trimester, and the surgical timing was also taken into account. This article recommends that in the second trimes- ter, diskectomy should be preferably performed in lateral decubitus to avoid aortocaval compression; finally, in the third trimester, only left lateral decubitus is recommended. ${ }^{5}$

The use of FHB monitoring during a nonobstetric surgery is a matter of debate: a recent survey of the Association of Professors of Gynecology and Obstetrics found that most respondents do not routinely perform intraoperative fetal monitoring, but simply monitor the fetus before and after the procedure. ${ }^{18}$ Chestnut's Obstetric Anesthesia recommends monitoring the FHB and uterine activity both before and after surgery. Intraoperative FHB monitoring may be considered when technically feasible, depending on the ease of monitoring, the type and site of the surgery, and the gestational age. In their article, Katz et al propose that until 20 weeks of gestation, there is no need for monitoring the FHB during surgery; from 20 to 23 weeks, monitoring is debatable and is mandatory from the 23rd week on. ${ }^{19}$

In the vast majority of the cases described, as in our case, gestation proceeded normally after surgery. ${ }^{1,5,13,16}$

\section{Conclusion}

There are many special considerations when treating a pregnant patient with nonobstetric disease, mainly when a surgical procedure is indicated.

With this case and literature review, we conclude that diskectomy can be indicated during pregnancy; however, the surgeon and the surgical team must be alert to the details described herein, as this information is important for the success of the procedure and for the well-being of both the mother and the newborn.

\section{Disclosures \\ Michel Kanas, none \\ Hugo Kunzle, none \\ Delio E. Martins, none \\ Luiz A. Kirsch, none \\ Eduardo B. Puertas, none \\ Marcelo Wajchenberg, none}

\section{References}

1 Brown MD, Levi AD. Surgery for lumbar disc herniation during pregnancy. Spine (Phila Pa 1976) 2001;26(4):440-443

2 Fast A, Shapiro D, Ducommun EJ, Friedmann LW, Bouklas T, Floman Y. Low-back pain in pregnancy. Spine (Phila Pa 1976) 1987;12(4): 368-371

3 Kristiansson P, Svärdsudd K, von Schoultz B. Serum relaxin, symphyseal pain, and back pain during pregnancy. Am J Obstet Gynecol 1996;175(5):1342-1347

4 LaBan MM, Perrin JCS, Latimer FR. Pregnancy and the herniated lumbar disc. Arch Phys Med Rehabil 1983;64(7):319-321

5 Han IH, Kuh SU, Kim JH, et al. Clinical approach and surgical strategy for spinal diseases in pregnant women: a report of ten cases. Spine (Phila Pa 1976) 2008;33(17):E614-E619

6 LaBan MM, Rapp NS, von Oeyen P, Meerschaert JR. The lumbar herniated disk of pregnancy: a report of six cases identified by magnetic resonance imaging. Arch Phys Med Rehabil 1995;76(5): 476-479 
7 Wang PI, Chong ST, Kielar AZ, et al. Imaging of pregnant and lactating patients: part 1, evidence-based review and recommendations. AJR Am J Roentgenol 2012;198(4):778-784

8 Shellock FG, Crues JV. MR procedures: biologic effects, safety, and patient care. Radiology 2004;232(3):635-652

9 ACOG Committee on Obstetric Practice. ACOG Committee Opinion. Number 299, September 2004 (replaces No. 158, September 1995). Guidelines for diagnostic imaging during pregnancy. Obstet Gynecol 2004;104(3):647-651

10 Houghton PE, Nussbaum EL, Hoens AM. Electrophysical agentscontraindications and precautions: an evidence-based approach to clinical decision. Physiother Can 2010;62:1-80

11 Miller RD. Miller's Anesthesia. 7th ed. Philadelphia, PA: Churchill Livingstone Elsevier; 2010

12 Van de Velde M. Nonobstetric surgery during pregnancy. In: Chestnut DH, ed. Obstetric Anesthesia: Principles and Practice. 4th ed. Philadelphia, PA: Mosby; 2009:337-359

13 Iyilikçi L, Erbayraktar S, Tural AN, Celik M, Sannav S. Anesthetic management of lumbar discectomy in a pregnant patient. J Anesth 2004;18(1):45-47

14 Kort B, Katz VL, Watson WJ. The effect of nonobstetric operation during pregnancy. Surg Gynecol Obstet 1993;177(4):371-376
15 Mazze RI, Källén B. Reproductive outcome after anesthesia and operation during pregnancy: a registry study of 5405 cases. Am J Obstet Gynecol 1989;161(5):1178-1185

16 Kim HS, Kim SW, Lee SM, Shin H. Endoscopic discectomy for the cauda equina syndrome during third trimester of pregnancy. J Korean Neurosurg Soc 2007;42(5):419-420

17 Brown MD, Brookfield KF. Lumbar disc excision and cesarean delivery during the same anesthesia. A case report. J Bone Joint Surg Am 2004;86-A(9):2030-2032

18 Kilpatrick CC, Puig C, Chohan L, Monga M, Orejuela FJ. Intraoperative fetal heart rate monitoring during nonobstetric surgery in pregnancy: a practice survey. South Med J 2010;103(3): $212-215$

19 Katz JD, Hook R, Barash PG. Fetal heart rate monitoring in pregnant patients undergoing surgery. Am J Obstet Gynecol 1976;125(2): 267-269

20 Friedman JM. Report of the Teratology Society Public Affairs Committee symposium on FDA classification of drugs. Teratology 1993;48:5-6

21 Kulay L Jr. Medicamentos na gravidez e lactação. 3rd ed. São Paulo, Brazil: Editora Manole; 2012 